\title{
An interventional study to improve the quality of analgesia in the emergency department
}

\author{
Michael Yanuka, MD; Dror Soffer, MD; Pinchas Halpern, MD
}

\begin{abstract}
Objective: We sought to document the adequacy of acute pain management in a high-volume urban emergency department and the impact of a structured intervention.

Methods: We conducted a prospective, single-blind, pre- and postintervention study on patients who suffered minor-to-moderate trauma. The intervention consisted of structured training sessions on emergency department (ED) analgesia practice and the implementation of a voluntary analgesic protocol.

Results: Preintervention data showed that only 340 of 1000 patients (34\%) received analgesia. Postintervention data showed that 693 of 700 patients $(99 \%)$ received analgesia, an absolute increase of $65 \%(95 \% \mathrm{Cl} 61 \%-68 \%)$, and that delay to analgesia administration fell from 69 (standard deviation [SD] 54) minutes to 35 (SD 43) minutes. Analgesics led to similar reductions in visual analog pain scale ratings during the pre- and postintervention phases $(4.5 \mathrm{~cm}, S D 2.0 \mathrm{~cm}$, and $4.3 \mathrm{~cm}, \mathrm{SD} 3.0 \mathrm{~cm}$, respectively).

Conclusion: Our multifaceted ED pain management intervention was highly effective in improving quality of analgesia, timeliness of care and patient satisfaction. This protocol or similar ones have the potential to substantially improve pain management in diverse ED settings.
\end{abstract}

Keywords: emergency department, analgesia, training, improvement, protocols

\section{RÉSUMÉ}

Objectif : Nous avons cherché à déterminer si la gestion de la douleur aiguë dans une salle d'urgence en milieu urbain est adéquate et quel serait l'impact d'une intervention structurée.

Méthodes : Nous avons réalisé une étude prospective, à simple insu, pré- et post-intervention, portant sur les patients ayant subi un traumatisme léger à modéré. L'intervention consistait en séances de formation structurées sur les pratiques analgésiques en salle d'urgence et la mise en application volontaire d'un protocole analgésique.

Résultats : Les données pré-intervention ont révélé que seulement 340 des 1000 patients (34\%) ont reçu une analgésie. Les données post-intervention ont indiqué, par ailleurs, que 693 des 700 patients (99\%) ont reçu un analgésique, ce qui correspond à une augmentation absolue de $65 \%$ [intervalle de confiance (IC) à $95 \%, 61$ à $68 \%$,], et que le retard d'administration d'un analgésique est passé de 69 minutes [écart-type (ÉT) de $54 \mathrm{~min}$ ] à 35 minutes (ÉT de $43 \mathrm{~min}$ ). L'administration d'analgésiques a entraîné une réduction des scores sur l'échelle visuelle analogue pendant les 
phases pré- et post-intervention [4,5 cm (ÉT de 2,0 cm) et 4,3 cm (ÉT de 3,0 cm) respectivement]. Conclusion : Notre intervention de gestion de la douleur aiguë à multiples facettes réalisée en salle d'urgence a été très efficace dans l'amélioration de la qualité de l'analgésie, l'accès rapide aux soins et la satisfaction des patients. Ce protocole ou des protocoles similaires peuvent améliorer considérablement la gestion de la douleur dans divers types de salles d'urgence.

\section{Introduction}

Many studies have reported that emergency physicians and nurses frequently undertreat pain and that most emergency department (ED) patients do not receive adequate, timely analgesia. ${ }^{1}$ This phenomenon, termed oligoanalgesia, is also common in the treatment of patients with chronic pain. ${ }^{1}$ The causes of oligoanalgesia include a disparity between patient and health care provider perceptions of pain severity and a greater provider focus on diagnostic testing and disease-modifying interventions (e.g., thrombolytics for myocardial infarction and laparotomy for acute abdomen). ${ }^{2}$ Other factors include the influence of patient sex and ethnicity, inadequate nurse and physician knowledge, fear of masking symptoms and concerns about addiction. ${ }^{2-5}$ Consequently, many patients who undergo otherwise appropriate ED investigation and treatment receive little or no pain management. ${ }^{5}$

The principles of pain management suggest that analgesia should be part of a patient's overall care plan and that

- health care providers require the appropriate knowledge base and practical pain management protocols,

- pain management champions should be appointed among the ED staff,

- the emotional and cognitive aspects of pain should be addressed,

- analgesia should be individualized,

- analgesia is provided in an anticipatory rather than a reactive fashion,

- combination therapy is generally most effective,

- a multidisciplinary team approach is optimal. ${ }^{6}$

We developed a multifaceted intervention that included an educational component for ED and consulting staff, as well as an acute pain management protocol. The aims of the present study were to assess the adequacy of ED analgesic management and to evaluate how the implementation of a structured, multifaceted intervention might improve it.

\section{Methods}

\section{Setting and subjects}

This prospective, single-blind, pre-post intervention study of adult ED subjects was conducted in a large tertiary university-affiliated hospital in Israel. ED physicians, nurses and patients were unaware of the purpose of the study. Institutional Ethics Review Board approval was obtained, waiving the need for patient informed consent because this was an observational study that posed minimal additional risk to patients.

Our ED is organized into surgical and medical sections with a combined annual census of 130000 patients. Emergency physicians are not available in sufficient numbers for clinical care of these patients, so injury management is provided mainly by orthopedic and surgical house staff under the emergency physician's supervision. Patients suffering from minor-to-moderate trauma (sprains, long bone fractures excluding the femur, lacerations requiring suturing, first- and second-degree burns) or renal colic were eligible. Patients younger than 18 years, those with impaired mental status or cardiorespiratory instability, and those who refused to assess pain using the visual analog scale (VAS) were excluded. We enrolled a convenience sample of patients presenting to the ED's surgical section on alternating weekday morning $(8 \mathrm{am}-4 \mathrm{pm})$ or evening shifts (4-11 pm). Eligible patients were identified by an anesthesiologist who was assigned full-time to the ED to manage trauma airways. He also collected all data for the duration of the study. Since the anesthesiologist's airway management duties were limited, he was able to devote the majority of his time to the study.

\section{Data collection}

We prospectively collected preintervention data on the state of analgesia practice between June and December 2001. We then developed an analgesia protocol that incorporated standardization of analgesia medications and an educational intervention to promote better analgesic practice. The educational intervention was aimed at physicians involved in treating minor-to-moderate injuries and renal colic in the surgical ED. Subsequently, we assessed changes in analgesia practice after the educational intervention. The attending anesthesiologist identified eligible subjects as they were admitted to the ED, collected study data during their ED stay, supported inexperienced staff 
and monitored the overall quality of analgesia practice in the ED; however, he did not interfere with individual patient care or provide analgesics to patients.

The following data were obtained on eligible patients in both the pre- and postintervention phases of the study: reason for ED visit; pain severity, assessed using a 10-cm VAS (a paper-based 10-cm nongraduated line, which patients were asked to mark with a pen) before and after analgesic administration; waiting time for first analgesic (patients were also stratified into nonsevere pain for VAS $0-5 \mathrm{~cm}$ and severe pain for VAS 6-10 cm); medications administered; patient satisfaction with ED analgesia, assessed on a 5-cm nongraduated VAS just before discharge; and the presence and quality of discharge analgesia instructions.

\section{Intervention}

The study intervention consisted of 3 components:

\section{Expanding the selection of available analgesics}

Analgesics available before the study included oral acetaminophen, dipyrone, acetylsalicylic acid, ibuprofen, naproxen, buprenorphine, parenteral diclofenac, meperidine, morphine and fentanyl. During the intervention phase acetaminophen with codeine and codeine plus ketamine were added.

\section{Introducing a standardized analgesia protocol}

The new pain protocol specified dipyrone, aspirin, acetaminophen, ibuprofen or naproxen for low-level pain (VAS 1-3), acetaminophen with codeine, buprenorphine, or dipyrone with ibuprofen for moderate pain (VAS 4-6), and intravenous morphine, fentanyl, ketamine and nerve blocks for severe pain (VAS 7-10).

\section{Education}

One of the authors (P.H.) provided structured teaching sessions on the principles and techniques of ED analgesia to ED physicians and nurses, as well as to orthopedic and general surgeons and residents providing care in the ED. Sessions included a 2-hour didactic small-group lecture and a 1-hour case-based discussion. Approximately 25 surgical, orthopedic and emergency residents taking

Table 1. Patient characteristics

\begin{tabular}{lccc} 
& \multicolumn{2}{c}{ Group; no. (and \%)* } & \\
\cline { 2 - 3 } Variable & $\begin{array}{c}\text { Preintervention; } \\
n=1000\end{array}$ & $\begin{array}{c}\text { Postintervention; } \\
n=700\end{array}$ & $\begin{array}{c}\text { Mean difference } \\
(95 \% \mathrm{Cl})\end{array}$ \\
\hline Mean (and & $37(19)$ & $36(8)$ & $1.0(-0.3$ to 2.32$)$ \\
SD) age, yr & & $420(60.0)$ & $1.0(-0.04$ to 0.06) \\
Male sex & $610(61.0)$ & $(78)$ & $10.0(6.3-14.0)$ \\
Injury & $(88)$ & $(12)$ & $4(0.7-10.0)$ \\
Back pain & $(8)$ & $(10)$ & $6(3.5-8.5)$ \\
Other & $(4)$ & & \\
\hline Cl $=$ confidence interval; SD $=$ standard deviation. & & \\
$*$ Unless otherwise indicated. & & \\
\hline
\end{tabular}

Table 2. Quality of analgesia before and after intervention

\begin{tabular}{|c|c|c|c|}
\hline \multirow[b]{2}{*}{ Variable } & \multicolumn{2}{|c|}{ Group; mean (and SD)* } & \multirow[b]{2}{*}{$\begin{array}{c}\text { Mean } \\
\text { difference } \\
(95 \% \mathrm{Cl})\end{array}$} \\
\hline & $\begin{array}{c}\text { Preintervention; } \\
\quad n=1000\end{array}$ & $\begin{array}{c}\text { Postintervention; } \\
\quad n=700\end{array}$ & \\
\hline $\begin{array}{l}\text { VAS pain score on } \\
\text { arrival, cm }\end{array}$ & $6.9(2.0)$ & $6.8(0.6)$ & 0.1 (-0.3 to 0.2$)$ \\
\hline $\begin{array}{l}\text { No. (and \%) of patients } \\
\text { receiving analgesia }\end{array}$ & $343(34.3)$ & $693(99)$ & $65(61-68)$ \\
\hline $\begin{array}{l}\text { Mean time to first } \\
\text { analgesic, min }\end{array}$ & $69(54)$ & $35(43)$ & 34 (29-39) \\
\hline $\begin{array}{l}\text { Pain reduction, } \mathrm{cm} \text { on } \\
10-\mathrm{cm} \text { VAS }\end{array}$ & $4.5(2.0)$ & $4.3(3.0)$ & 0.0 (-0.3 to 0.3$)$ \\
\hline $\begin{array}{l}\text { Patient satisfaction, } \mathrm{cm} \\
\text { on } 5-\mathrm{cm} \text { VAS }\end{array}$ & $3.4(1.2)$ & $4.0(1.3)$ & $0.6(0.5-0.7)$ \\
\hline
\end{tabular}


call in the trauma-surgical section of the ED underwent the session within 1 month. During the 3-month period following training sessions, 1 of the authors (M.Y.) performed a care quality follow-up, including daily spot checks of at least 5-10 patient charts and repeated personal conversations with orthopedic and surgery residents. Real-time consultation capability to ED staff by a senior emergency physician who is also an anesthesiologist experienced in pain management (P.H.) was provided upon request of the clinical team members throughout the study period.

\section{Postintervention phase}

The postintervention data collection was a repetition of the phase 1 protocol, enrolling an additional 700 patients.

\section{Data analysis}

Binary data were summarized using proportions, and continuous data were summarized using means and standard deviations. Pain level, measured on a 10-cm VAS, was viewed as a quantitative variable. ${ }^{7}$ The precision of demographic and clinical pre- and postintervention data were evaluated using 95\% confidence intervals (CIs) where appropriate. SPSS version 11.0 (SPSS Inc.) was used for the analysis.

\section{Results}

One thousand patients were evaluated during the preintervention phase and 700 during the postintervention phase. Table 1 shows that the study groups were demographically similar, as were the proportions with injury and back pain. Table 2 shows that only $34 \%$ of preintervention patients received analgesia and that this increased to $99 \%$ during the post-intervention phase (absolute treatment effect, 65\%; $95 \%$ CI $61 \%-68 \%$ ). Ninety-six percent of patients received specific instructions and prescriptions postintervention, compared with $16 \%$ preintervention.

The mean waiting time for the first administration of analgesia significantly improved postintervention, decreasing from 69 to 35 minutes (absolute treatment effect, $34 \mathrm{~min}$; 95\% CI 29-39). During the postintervention phase, the waiting time was significantly lower for patients with severe pain (defined as 6-10 on the 10-cm VAS, $77.5 \%$ of group): 27.7 (standard deviation [SD] 35.1) minutes, compared with a mean of 60.5 (SD 57.8) minutes for patients with low pain levels (VAS 1-5, 22.5\% of patients). Table 2 also shows that patient satisfaction scores increased from 3.4 to 4.0 , a difference of $-0.6 \mathrm{~cm}(95 \% \mathrm{CI}-0.7$ to -0.5$)$ on the 5-cm VAS scale.

\section{Discussion}

Many studies have shown that ED patients receive inadequate pain relief, ${ }^{4-68-11}$ and are often discharged without the necessary prescription for analgesics or instructions for their use. Children are most frequently undertreated because of fears of opioid-related complications, especially in the setting of multiple trauma and head injury. ${ }^{11}$ Wilson and Pendleton used the term "oligoanalgesia" to describe the endemic undertreatment of pain, ${ }^{1}$ and a large body of literature focuses on the need to improve the quality of acute ED pain management. ${ }^{6}$ This study shows that our multifaceted intervention was highly effective in improving the quality of analgesia, the timeliness of care and patient satisfaction.

Previous investigators have made many suggestions for improving the state of oligoanalgesia. ${ }^{12}$ Training courses for ED staff have improved the quality of analgesic treatment in some studies, ${ }^{12-14}$ but had only limited impact in others. For example, Nelson and colleagues reported an $11 \%$ increase in analgesic use (from 25\% to 36\%) and a 39-minute reduction in time-to-analgesic (from 152 to $113 \mathrm{~min}) .{ }^{15}$ Pain management protocols that encourage intravenous rather than intramuscular opioids have shown clear benefit, ${ }^{13}$ as have nurse-initiated opioid protocols. ${ }^{15,16}$ Femoral and 3-in-1 nerve blocks have improved analgesia for patients with femoral neck fractures. ${ }^{17,18}$ Finally, the obligatory inclusion of pain pathophysiology and treatment into medical school curricula has been recommended, ${ }^{6}$ an idea that we applaud.

Limited improvement in ED analgesic practice is most likely a result of entrenched opinions among ED staff, heavy workloads that challenge even the provision of essential medical care, and the lack of coherent, enforced pain protocols. The multifaceted intervention described here incorporated a number of approaches in an attempt to overcome these problems. First, our preintervention data, which confirmed a poor quality of ED pain control, was helpful in convincing physicians of the need for change and in developing a site-specific educational approach. The protocol for pain assessment and treatment was developed and implemented to standardize and enhance previously diverse approaches, and a senior physician trained in pain control (P.H.) served as department champion, providing support for inexperienced staff and overseeing the quality of ED analgesia practice.

The almost universal administration of analgesia during the postintervention phase was the result of several factors, including high motivation of the orthopedic and surgical teams, enhanced knowledge of pain management, good 
buy-in to the pain improvement strategy, a simple protocol, awareness that analgesic practice was being monitored and the influence of their ED colleagues. Taken together, these factors resulted in a dramatic improvement in the quality of analgesia practice for minor-to-moderate trauma in our ED. The encouraging results have motivated all of the staff to expend much effort that will hopefully be sustained over time.

\section{Limitations}

The primary limitations of this study are its short duration and the lack of follow-up data. Although the percentage of patients who were given analgesia increased dramatically, the actual effect of analgesia was unchanged. A longer term study is necessary to ensure sustained effectiveness. External validity is a concern for several reasons: Israeli ED care systems differ from North American systems in that orthopedic surgeons, rather than emergency physicians, provide the bulk of minor-to-moderate trauma care. Further, the health care providers in our setting were mainly residents, and it is possible that attending-level physicians may be more resistant to protocol adoption. In addition, some ED environments might experience less cooperation from staff. The importance of such cooperation cannot be overstated, and our intervention may not be ideal for all settings.

Our "before-after" design is a potential limitation, since we cannot exclude the possibility that other concurrent factors may have contributed to the improved analgesic practice we witnessed, although we are not aware of any such factors that would explain the profound improvement seen. The study design did not allow us to differentiate between the various components of the intervention, nor can we exclude the possibility that there were other contributing factors. Finally, future studies should consider the use of more robust designs, including multiple baseline comparisons, cluster randomization or stepped wedge designs, to confirm our findings. ${ }^{19-21}$

\section{Conclusion}

Our multifaceted ED pain management intervention was highly effective in improving the quality of analgesia, the timeliness of care and patient satisfaction. This protocol or similar ones have the potential to substantially improve pain management in diverse ED settings.

Competing interests: None declared.

\section{References}

1. Wilson JE, Pendelton JM. Oligoanalgesia in the emergency department. Am J Emerg Med 1989;7:620-3.

2. Wall D, Melzack R. Textbook of pain, 4th ed. London (UK): Churchill Livingstone, 1999. p. 448.

3. Guttman S. Halpern P. Effects of gender on pain perception and treatment in the emergency department. Abstract presented at the First Mediterranean Emergency Medicine Congress, Stresa, Italy, September 2001.

4. Todd KH, Deaton C, D'Adamo AP, et al. Ethnicity and analgesic practice. Ann Emerg Med 2000;35:11-3.

5. Jones JS, Johnson K, McNinch M. Age as a risk factor for inadequate emergency department analgesia. Am J Emerg Med 1996;14:157-60.

6. Ducharme J. Acute pain and pain control: state of the art. Ann Emerg Med 2000;35:592-602.

7. Myles PS, Troedel S, Boquest M, et al. The pain visual analog scale: Is it linear or nonlinear? Anesth Analg 1999;89:1517-20.

8. Morgan-Jones R. Pre-operative analgesia after injury. Injury 1996;27:539-41.

9. Jantos TJ, Paris P, Menegazzi JJ, et al. Analgesic practice for acute orthopedic trauma pain in Costa Rican emergency department. Ann Emerg Med 1996;28:145-9.

10. Lewis LM, Lasater LC, Brooks CB. Are emergency physicians too stingy with analgesics? South Med J 1994;87:1-9.

11. Friedland LR, Kulick RM. Emergency department analgesic use in pediatric trauma victim with fractures. Ann Emerg Med 1994; 23:203-7.

12. Jones JB. Assessment of pain management skills in emergency medicine residents: the role of pain education program. J Emerg Med 1999;17:349-54.

13. Kelly AM. A process approach to improving pain management in the emergency department: development and evaluation. J Accid Emerg Med 2000;17:185-7.

14. Sucov A, Nathanson A, Proano L, et al. An educational program can increase the likelihood of fracture patient receiving analgesia in the ED. Acad Emerg Med 2001;8:427.

15. Nelson BP, Cohen D, Lander O, et al. Mandated pain scales improve frequency of ED analgesic administration. Am J Emerg Med 2004;22:582-5.

16. Kelly AM, Brumby C, Barnes C. Nurse-initiated, titrated intravenous opioid analgesia reduces time to analgesia for selected painful conditions. CJEM 2005;7:149-54.

17. Rudman N, McIlmail D. Emergency department evaluation and treatment of hip and thigh injuries. Emerg Med Clin North Am 2000;18:29-66.

18. Fletcher AK, Rigby AS, Heyes FL. Three-in-one femoral nerve block as analgesia for fractured neck of femur in the emergency department: a randomized, controlled trial. Ann Emerg Med 2003;41:227-33.

19. Hersen M, Bellack AS. A. Multiple-baseline analysis of socialskills training in chronic schizophrenics. J Appl Behav Anal 1976;9:239-45.

20. Campbell MJ. Cluster randomized trials in general (family) practice research. Stat Methods Med Res 2000;9:81-94.

21. Brown CA, Lilford, RJ. The stepped wedge trial design: a systematic review. BMC Med Res Methodol 2006;6:54.

Correspondence to: Dr. Pinchas Halpern, Emergency Department, Tel Aviv Sourasky Medical Center, 6 Weitzman St., Tel Aviv 64239, Israel; dr_halperin@ tasmc.health.gov.il 